Case Report

\title{
A study of risk factors for acute lower respiratory tract infections (ALRTI) in children aged 1 month to 5 years attending to a tertiary care hospital, Eluru, Andhra Pradesh, India
}

\author{
Bekkam M. ${ }^{1}$, Vasundhara A. ${ }^{2}$ \\ ${ }^{1}$ Dr. Manohar Bekkam, Assistant Professor, Department of Pediatrics, ASRAM Medical College, Eluru, Andhra Pradesh, \\ India, ${ }^{2}$ Dr. Arigela Vasundhara, Professor, Department of Pediatrics, ASRAM Medical College, Eluru, Andhra Pradesh, \\ India.
}

Corresponding Author: Dr. Arigela Vasundhara, Professor, Department of Pediatrics, ASRAM Medical College, Eluru, Andhra Pradesh, India. Email: drarigelav@yahoo.com

\begin{abstract}
Introduction: Acute respiratory infections are a leading cause of morbidity and mortality in under-five children in developing countries with nearly 156 million new episodes each year, of which India accounts for a bulk of 43 million. According to Child Health Epidemiology Reference Group (CHERG) latest estimates for 2010, pneumonia was responsible for 0.397 million of total estimated 1.682 million under-5 deaths in India. Objective: The present study was undertaken to study the various risk factors of Acute lower respiratory tract infections (ALRTI) in children aged 1 month to 5 years. Methods: In the present study100 ALRTI cases belong to the age group of 1 month to 5 years fulfilling WHO criteria for pneumonia who were attended to the department of Pediatrics, ASRAM Medical College from August 2017 to August 2018 were evaluated for risk factors after obtaining parental consent. Results: Parental illiteracy $(p=0.000 *)$, overcrowding $\left(\mathrm{p}=0.0000^{*}\right)$, incomplete immunization $\left(\mathrm{p}=0.0000^{*}\right)$, lack of exclusive breast feeding $\left(\mathrm{p}=0.0004^{*}\right)$, low birth weight $\left(\mathrm{p}=0.000^{*}\right)$, use ofbiomass fuels for lighting $\left(\mathrm{p}=0.0002^{*}\right)$, mud/ cowdung flooring $\left(\mathrm{p}=0.0088^{*}\right)$ were identified as potential risk factors for severe ALRTI. Conclusion: The present study has identified various sociodemographic, nutritional and environmental risk factors for ALRTI which can be tackled by effective health education of the community and effective training of peripheral health personnel.
\end{abstract}

Keywords: ALRTI (Acute lower respiratory tract infection), Pneumonia, risk factors

\section{Introduction}

Acute Lower Respiratory Tract Infection (ALRTI) is the leading cause of under-5 childhood morbidity in the world, with nearly 156 million new episodes each year, of which India accounts for a bulk of 43 million. The mortality burden is 1.9 million per year, out of which India accounts for around four hundred thousand deaths per year [1].

According to Child Health Epidemiology Reference Group (CHERG) latest estimates for 2010, Pneumonia was responsible for 0.397 million of total estimated 1.682 million under-5 deaths in India [2]. In India pneumonia was responsible for about $18 \%$ of all under five deaths [3]. In Andhra Pradesh alone 3045868 were affected due to pneumonia and 1526522 were males and 1519346 were females and among them 189 died of

Manuscript received: $6^{\text {th }}$ September 2018

Reviewed: $16^{\text {th }}$ September 2018

Author Corrected: $24^{\text {th }}$ September 2018

Accepted for Publication: $30^{\text {th }}$ September 2018 severe pneumonia [3]. Childhood pneumonia is caused by a combination of exposure to risk factors related to the host, the environment and infection. Under nutrition, use of solid fuels in a household, overcrowding, lack of exclusive breastfeeding, low degree of maternal education, which are often characteristics of poor households are cited by many studies $[4,5,6]$ as the common risk factors for occurrence of ALRTI [6].

Therefore, it is necessary to study the risk factors which may perpetuate the development of ALRTI. Identification of these modifiable risk factors for ALRTI may help in reducing the burden of disease, and understanding of whichwill further help in the prevention of occurrence of ALTRI and its complications. So the present study was conducted to analyze the risk factors for ALRTI in children aged 1 month to 5 years. 


\section{Aims \& Objectives}

To study the risk factors of acute lower respiratory tract infections in children aged 1 month to 5 years drawn from the rural areas surrounding ASRAM hospital, Eluru, Andhra Pradesh, India.

\section{Materials and Methods}

Design: A prospective study of ALRTI in children aged 1 month to 5 years conducted at ASRAM Medical College, Eluru, West Godavari district, Andhra Pradesh, India.

Source of data: Children admitted in ASRAM hospital with clinical diagnosis of ALRTI as per WHO criteria from August 2017 to August 2018.

Inclusion criteria: Children with ALRTI aged 1 month to 5years.

\section{Exclusion criteria}

- Children less than 1 month and more than 5 years of age.

- Children with any underlying chronic respiratory illness.

- Children with any underlying chronic cardiacillness.

Method of collection of data- Children in the age group of 1 month to 5 years admitted with ALRTI during the study period were enrolled in the study as cases. A case of ALRTI can be pneumonia or severe pneumonia $[17,18]$.

Pneumonia is defined as per ARI control programme [16] as "presence of cough with fast breathing of more than $60 / \mathrm{min}$ in less than 2 months of age, more than $50 / \mathrm{min}$ in 2 months to 12 months of age and more than $40 / \mathrm{min}$ in 12 months to 5 years of age, with or without the presence of chest wall indrawing, and theduration of illness being less than 30 days".

The presence of refusal of feeds, central cyanosis, lethargy or unconsciousness, convulsions, stridor in a calm child, severe malnutrition was taken as evidence of severe pneumonia $[17,18]$. Verbal informed consent of the child's caretaker was obtained. A detailed history and physical examination was done according to a predesigned proforma to elicit various potential risk factors and relevant history. Age of the child was recorded in completed months.

A detailed history of relevant symptoms like fever, cough, rapid breathing, chest indrawing, refusal of feeds, lethargy, wheezing etc. was taken. Past history of similar complaints was also taken. History of birth weight noted, family history and details of the parents literacy noted. History of Immunization was taken from parents and verified by checking the documents wherever available. History of initiation and continuation of exclusive breast feeding and weaning was recorded.

Dietaryintake of child prior to current illness was calculated by 24 hour dietary recall method. History of URI in the family members in the preceding 2 weeks was recorded. History of smoking by the family members and details of cooking fuel used was recorded. Details of the housing conditions like type of flooring, source for lighting, type of kitchen were also obtained. Socio economic status grading was done according to modified Kuppuswamy" s classification. A detailed examination of each child was done. Respiratory rate and heart rate were measured for one minute, when the child was quiet. A detailed anthropometry was done and malnutrition was graded according to Indian Academy of Pediatrics classification. Severity of respiratory distress was assessed in each child. Pallor and other signs of vitamin deficiencies were recorded.

A detailed systemic examination was done. Routine hematological investigations were done in all cases to know the degree of anemia and blood count, chest x-ray was done in all cases to categorize the ALRTI into clinical entities and to detect complications, if any. Other specific investigations were done as per requirement in individual cases and all the cases were treated as per the standard protocol depending on the type of ALRTI.

Analysis: Appropriate tables and graphical representtations were used to display the data. Odds ratio was calculated, Chi square test was used. A "p" value $<0.05$ was taken as significant.

\section{Results}

Among the 100 cases of ALRTI studied, 78 (78\%) children suffered with Pneumonia and 22 (22\%) children suffered with Severe pneumonia. In these 100 cases, 62 children (62\%) were infants and outof 22 cases of severe pneumonia, 14 children (63.6\%) were infants. Among the 100 cases of ALRTI, $69(69 \%)$ were males, 31 (31\%) were females, out of 22 cases of severe pneumonia $15(68.1 \%)$ were male children and $07(31.9 \%)$ were female children. 


\section{Case Report}

1. Maternal literacyand severity of pneumonia- Of the 100 ALRTI cases in the study, $31 \%$ had illiterate mothers. Significant association $(\mathrm{p}=0.0001 *)$ was found between maternal illiteracy and severe pneumonia.

\begin{tabular}{|c|c|c|c|}
\hline Literacy & Severe pneumonia & Pneumonia & \\
\hline Illiterate & $15(68.1 \%)$ & 16 & 31 \\
\hline Literate & $07(31.9 \%)$ & 62 & 69 \\
\hline Total & $\mathbf{2 2}(\mathbf{1 0 0} \%)$ & $\mathbf{7 8}$ & $\mathbf{1 0 0}$ \\
\hline
\end{tabular}

Odds ratio 8.30 Chi $2=16.07 \mathrm{p}=0.0001^{*}$

2. Paternal Literacy and severity of pneumonia- Of the 100 ALRTI cases in the study, $20 \%$ had illiterate fathers. Significant association $\left(\mathrm{p}=0.000^{*}\right)$ was found between pneumonia severity and paternal illiteracy.

Odds ratio 10.50 Chi $2=18.36 \mathrm{CI}=3.8-28.7 \mathrm{p}=0.000^{*}$

3. Birth Weight and severity of pneumonia- Among the 100 ALRTI cases, $18 \%$ were low birth weight. Significant association $\left(\mathrm{p}=0.000^{*}\right)$ was found between low birth weight and severe pneumonia.

\begin{tabular}{|c|c|c|c|}
\hline Low birth weight & Severe Pneumonia & Pneumonia & \\
\hline Present & $14(63.6 \%)$ & 04 & 18 \\
\hline Absent & $08(36.4 \%)$ & 74 & 82 \\
\hline Total & $\mathbf{2 2}(\mathbf{1 0 0 \% )}$ & $\mathbf{7 8}$ & $\mathbf{1 0 0}$ \\
\hline
\end{tabular}

Odds ratio 32.38 Chi2 $=35.93 \mathrm{CI} 11.0-95.4 \mathrm{p}=0.000^{*}$

4. Exclusive breast feeding and severity of pneumonia- Of the 100 ALRTI cases $38 \%$ were not exclusively breast fed. Significant association $(\mathrm{p}=0.0004 *)$ was found between severe pneumonia and lack of exclusive breast feeding.

\begin{tabular}{|c|c|c|c|}
\hline Exclusive breast feeding & Severe Pneumonia & Pneumonia & \\
\hline Absent & $16(72.8 \%)$ & 22 & 38 \\
\hline Present & $06(27 \%)$ & 56 & 62 \\
\hline Total & $\mathbf{2 2}(\mathbf{1 0 0} \%)$ & $\mathbf{7 8}$ & $\mathbf{1 0 0}$ \\
\hline
\end{tabular}

Odds ratio $6.79 \mathrm{Chi} 2=12.61 \mathrm{CI}=2.5-18.2 \mathrm{p}=0.0004 *$

\section{Immunization and severity of pneumonia}

Of the 100 ALRTI cases studied, $39 \%$ were incompletely immunized for age. Significant association $\left(\mathrm{p}=0.0000^{*}\right)$ was found between severe pneumonia and incomplete immunization status.

\begin{tabular}{|c|c|c|c|}
\hline Immunization & Severe Pneumonia & Pneumonia & 39 \\
\hline Incomplete for age & $18(81.9 \%)$ & 21 & 61 \\
\hline Complete for age & $04(18.1 \%)$ & 57 & $\mathbf{1 0 0}$ \\
\hline Total & $\mathbf{2 2}(\mathbf{1 0 0 \% )}$ & $\mathbf{7 8}$ \\
\hline
\end{tabular}

Odds ratio $12.21 \mathrm{Chi} 2=19.49 \mathrm{CI}=4.3-35.0 \mathrm{p}=0.0000^{*}$

6. Type of flooring and severity of pneumonia- Among the 100 ALRTI cases, $84 \%$ were found to be living in houses with pucca flooring. Significant association $\left(\mathrm{p}=0.0088^{*}\right)$ was found between severe pneumonia and mud or cow dung type of flooring.

Odds ratio $=5.00 \mathrm{Chi} 2=8.702 \mathrm{CI}=1.7-14.6 \mathrm{p}=0.0088^{*}$ 


\section{Case Report}

7. Source for lighting and severity of pneumonia- Among the 100 ALRTI cases, $71 \%$ were found to be living in houses utilizing electricity for lighting. The remaining $29 \%$ were living in houses using various biomass fuels for lighting. Significant association $(\mathrm{p}=0.0002 *)$ was found between usage of biomass fuels for lighting and severe pneumonia.

\begin{tabular}{|c|c|c|c|}
\hline Source for lighting & Severe Pneumonia & Pneumonia & \\
\hline Biomass fuels & $14(63.6 \%)$ & 15 & 29 \\
\hline Electricity & $08(36.4 \%)$ & 63 & 71 \\
\hline Total & $\mathbf{2 2}(\mathbf{1 0 0} \%)$ & $\mathbf{7 8}$ & $\mathbf{1 0 0}$ \\
\hline
\end{tabular}

Odds ratio $=7.35 \mathrm{Chi} 2=14.35 \mathrm{CI}=2.8-19.3 \mathrm{p}=0.0002 *$

8. Overcrowding and severity of pneumonia- Overcrowding was present in $86 \%$ among the 100 ALRTI cases. Significant association $\left(\mathrm{p}=0.0000^{*}\right)$ was found between overcrowding and pneumonia severity.

Odds ratio $=0.02 \mathrm{Chi} 2=34.31 \mathrm{CI}=0.0-0.1 \mathrm{p}=0.0000^{*}$

\section{History of upper respiratory tract infection (URI) in the family ( $\leq 2$ weeks) and severity of pneumonia}

Of the 100 ALRTI cases, $14 \%$ had history of at least one family member having or having had a URI in the preceding 2 weeks. However, nosignificant association $(\mathrm{p}=0.0923)$ was found between history of upper respiratory tract infection in the family and pneumoniaseverity.

Odds ratio $=3.28$ Chi $2=2.83 \mathrm{CI}=1.0-10.3 \mathrm{p}=0.0923$

Risk Factors for Severe pneumonia.

\begin{tabular}{|c|c|c|}
\hline Risk factor & Severe pneumonia & Association \\
\hline Maternal Illiteracy & $68.1 \%$ & Significantp $=0.0001^{*}$ \\
\hline Paternal Illiteracy & $54.5 \%$ & Significant $\mathrm{p}=0.000^{*}$ \\
\hline Low birth weight & $63.6 \%$ & Significant $\mathrm{p}=0.000^{*}$ \\
\hline Non Exclusivebreast feeding & $72.8 \%$ & Significantp $=0.0004^{*}$ \\
\hline Incomplete Immunization & $81.9 \%$ & Significantp $=0.0000^{*}$ \\
\hline Mud/Cowdung flooring & $36.4 \%$ & Significant $\mathrm{p}=0.0088^{*}$ \\
\hline Usage of Biomass fuels as source of lighting & $63.6 \%$ & Significantp $=0.0002^{*}$ \\
\hline Overcrowding & $45.5 \%$ & Significantp $=0.0000^{*}$ \\
\hline H/o URI in the family & $27.2 \%$ & Non Significant $\mathrm{p}=0.0923$ \\
\hline
\end{tabular}

\section{Discussion}

In the present study, 100 ALRTI cases were studied for the risk factors whose association can result in progression of pneumonia into severe pneumonia.

Acute lower respiratory tract infections (ALRTI) are the commonest causes of morbidity and mortality among children under 5 years of age, especially in developing countries. In the present study most of ALRTI cases are infants $(62 \%)$, which goes in accordance with studies by Amitoj et.al [13] 61\%, Banajeh et al [14]74.1\%, Zhang $Q$ et al [15] 76\%. Parental literacy may extend a protective effect on children and thus guard against ALRTI by increasing awareness about preventive practices and early medical consultation. Savitha et al [4] with $63.46 \%$ maternal illiteracy showed strong association between the mother's illiteracy and the occurrence of LRTI. In the present study $31 \%$ of mothers were illiterate, and this result was similar to the studies by Yousif et al [5] and Broor et al [7] which showed maternal illiteracy of $16.2 \%$ \& $34.8 \%$ respectively.

Children of illiterate mothers had (odds ratio 8.30) 8.30 times of risk of having severe pneumonia compared to children of literate mothers. In the present study significant association $\left(\mathrm{p}=0.0001^{*}\right)$ was found between 
Case Report

maternal illiteracy and pneumonia severity. Similar results were reported by Yousif et al [5]. In the present study $20 \%$ of fathers were illiterate, and Yousif et al [5] and Broor et al [7] studies showed a similar paternal illiteracy of $16.2 \% \& 17.4 \%$ respectively. Children of illiterate fathers had (odds ratio 10.50) 10.50 times of risk of having severe pneumonia compared to children of literate fathers. In the present study significant association $\left(\mathrm{p}=0.000^{*}\right)$ was found between pneumonia severity and paternal illiteracy, similar to the findings of Yousif et al [5].

The preventive role of immunization in ALRTI prevention has been stressed upon extensively. The present study shows 39\% were incompletely immunized children, and this is similar to the Savitha et al [4] and Yousif et al[5] studies which showed $21.15 \%$ and $38.2 \%$ incompletely immunized children respectively. Children who were incompletely immunized for the age had (odds ratio 12.21) 12.21 times of risk of having severe pneumonia compared to children whose immunization is complete for the age. In the present study, significant association $\left(\mathrm{p}=0.0000^{*}\right)$ was found between incomplete immunization status and pneumonia severity, similar to the findings of Broor et al [8], Yous if et al[5] and Savitha et al [4]. Mothers utilizing immunization services are better aware of health care facilities and probably seek early consultation for illness of their children, which probably avoids severe illness. Also immunization against certain diseases like measles, Haemophilus influenza type b may protect the child against ALRTI.

The spread of infection via respiratory droplets may be aggravated by overcrowding. In the present study $86 \%$ cases were associated with overcrowding, which is similar to the results of Yousif et al [5] (71.6\%). In the present study significant association $\left(\mathrm{p}=0.0000^{*}\right)$ was found between overcrowding and pneumonia severity. Similarly, Savitha et al [4]also showed significant association $(\mathrm{p}=<0.001)$.

In the present study of the 100 ALRTI cases, $38 \%$ were not exclusively breast fed and significant association $\left(p=0.0004^{*}\right)$ was found between lack of exclusive breast feeding and severity of pneumonia. Childrenwho were not received exclusive breast feeding had (odds ratio 6.79) 6.79 times ofrisk for having severe pneumonia compared to children who received exclusive breast feeding. In astudy by Victoria $\mathrm{CG}$ et $\mathrm{al}[8]$ on acute lower respiratory tract infection specific mortality relative to breastfed infants, those,who also received artificial milk had a risk of death by 1.6 times and non-breastfed infants had a risk of death by 3.6 times. Breastfeeding confers protective benefits upon the child in the form of transferred maternal antiinfective factors that guard against severe microbial disease. Exclusive breastfeeding for first 6 months of life not only protects against severe pneumonia but also protects from development of asthma andother allergic disorders. Colostrum contains antibodies against Respiratory syncytial virus and also a high concentration of C3, Ig A and lactoferrin which protect against gram negative organisms [9].

Cases with a history of low birth weight constituted $18 \%$ in the present study. This was similar to the study by Yousif et al [5](17.2\%). Children with history of low birth weight had (odds ratio 32.38) 32.38 times of risk of having severe pneumonia compared to children of normal birth weight. In the present study significant association $\left(\mathrm{p}=0.000^{*}\right)$ was found between low birth weight and pneumonia severity. The low birth weight baby has a poor pulmonary function and low immunity, which makes it more liable to have respiratory infection.

Mud floors tend to crack and serve as breeding sites for insects and may harbour infectious microbes. Also, excessive dirt may be produced as a result of the floor breaking up which mayincrease ALRTI risk. In the present study $16 \%$ of cases had mud and cow dung as a flooring in their houses, which was similar to the findings Brooret al [7](12.9\%). Children living in houses with mud/cow dung flooring had (odds ratio 5.00) 5.00 times of risk of having severe pneumonia compared to children living in houses with pucca flooring. In the present study, significant association $\left(\mathrm{p}=0.0088^{*}\right)$ was found between pneumonia severity and mud or cow dungtype of flooring.

The main mode of light source used is electricity (71\%) in the present study. Other sources like kerosene lamps and biomass fuels comprised $29 \%$ in the present study. Savitha et al[4] study reported similar results with $66 \%$ people using electricity. Children who were living in houses which use biomass fuels for lighting had (odds ratio 7.35) 7.35 times of risk of having severe pneumonia compared to children living in houses with electricity as source for lighting.

In the present study, significant association $(\mathrm{p}=0.0002 *)$ was found between pneumonia severity and biomass fuel usage for lighting. Kerosene lamps emit harmful hydrocarbon particulate matter, which is due to a size smaller than $2.5 \mu$ can penetrate deep into the lungs, thereby increasing the risk of lower respiratory infection [10]. In the present study history of upper respiratory 
Case Report

tract infection in the familypresent in $14 \%$ of the cases. Similar results were found in the study by Savitha et al[4] (9\%). Children with history of URI in the family had (odds ratio 3.28) 3.28 times of risk of having severe pneumonia compared to children with no history of URI in the family, however, in the present study no significant association $(p=0.0923)$ was found between history of upper respiratory tract infection in the family and pneumonia severity.

\section{Conclusion}

The present study identified various risk factors associated with severe pneumonia. The sociodemographic risk factors of significance were parental illiteracy, incomplete age-appropriate immunization, and overcrowding.

The other risk factors of significance were nutritional, like lack of exclusive breast feeding, low birth weight, environmental risk factors found were use of biomass fuels for lighting, mud/cowdung flooring in the house.

The above mentioned factors can be countered in the following ways:

- Health education for the community regarding healthcare practices and harmful effects of biomass fuel usage for lighting and overcrowding and the importance of proper ventilation in houses.

- Effective utilization of "under-fiveclinics" to ensure availability of proper nutrition to combat malnutrition and anemia, and up to date Immunization to under-5 children.

- Effective implementation of the existing national health programmes to improve the health status of under-five children.

\section{Contributions}

- Dr. Manohar Bekkam wrote the first draft of the manuscript.

- Dr. Manohar Bekkam helped in data collection,

- Dr. Arigela Vasundhara helped in writing manuscript and did primary corrections in the manuscript.

- Dr. ArigelaVasundhara made final corrections of manuscript before submission.

- Both authors approved the submission of this version of the manuscript and takes full responsibility for the manuscript. None of the authors have any conflict of interest.

\section{What this study adds to existing knowledge?}

Maternal and paternal illiteracy is associated with severity of pneumonias in children along with other socio demographic factors like mud/cow dung flooring, biogas fuel usage and partial immunization.

Funding: Nil, Conflict of interest: None initiated, Perission from IRB: Yes

\section{References}

1. Rudan I, Boschi-Pinto C, Biloglav Z, et al. Epidemiology and etiology of childhood pneumonia. Bull World Health Organ. 2008 May; 86(5):408-16.

2. Liu L, Johnson HL, Cousens S, et al. Global, regional, and national causes of child mortality: an updated systematic analysis for 2010 with time trends since 2000. Lancet. 2012 Jun 9; 379 (9832): 2151-61. doi: 10.1016/ S0140-6736(12) 60560-1. Epub 2012 May 11.

3. National health profile 2018. Government of India, DGHS, Ministry of health and familywelfare, New Delhi.

4. Savitha MR, Nandeeshwara SB, Pradeep Kumar MJ, et al. Modifiable risk factors for acute lower respiratory tract infections. Indian J Pediatr. 2007 May; 74 (5): 477-82.

5.Yousif TK, Khaleq BANA. Epidemiology of acute lower respiratory tract infections among children under five years attending Tikrit general teaching hospital. Middle eastern J Fam Med. May 2006; 4 (3): 48-51

6. Rudan, I., Brien, K., Nair, H., liu, L., Theodoratu, E., Qazi, S., Luksic, E., Walker, C., Black, R., and Campbell, H. Epidemiology and etiology of childhood pneumonia in 2010: estimates of incidence, severe morbidity, mortality, underlying risk factors and causative pathogens for 192 countries. $J$ Glob Health. 2013 Jun; 3(1): 010401

7. Broor S, Pandey RM, Ghosh M, MaitreyiRS, Lodha $\mathrm{R}$, Singhal TS et al. Risk factors for severe acute lower respiratory tract infections in under-five children. Indian Pediatr.2001Dec; 38(12): 1361-1369.

8. Victora CG, Smith PG, Vaughan JP, et al. Evidence for protection by breast-feeding against infant deaths from infectious diseases in Brazil. Lancet. 1987 Aug 8; 2 (8554):319-22. 


\section{Case Report}

9. Illingworth RS, Normal breast feeding-physiology, chemistry and advantages. In The normal child- some problems of the early years and their treatment. Eds: Illingworth. R.S, $10^{\text {th }}$ edition, New York; Churchill Living stone.1996; P3-12

10. Sharma S, Sethi GR, Rohtagi A, Indoor air quality and acute lower respiratory infection in Indian urban slums. Environ Health Perspect. 1998 May; 106(5): 291-7. doi:10.1289/ehp. 98106291

11. Sikolia DN, Mwololo K, CheropH, Hussein, A, Juma, M, Kurui, J et al. The prevalence of acute respiratory infections and the associated risk factors: A study of children under five years of age in Kibera Lindi Village, Nairobi, Kenya. J Nal/.Inst Public Health 2002; 51(1): 67-72.

12. Azize HB, Zulkifli HI, Kasim MS. Protective and risk factors for acute respiratory infection in hospitalized urban Malaysian children : a case control study. Southeast Asian J Trop Med Public Health. 1995 Jun; 26 (2):280-285.

13. Amitoj Singh Chhina, Chandrakala R. Iyer, Vinod Kumar Gornale, Nagendra katwe, Sushma S, Harsha P.J, Chandan C.K. Clinical Profile of Acute Lower Respiratory Tract Infections in Children between 2 months to 5 Years. Journal of Evidence based Medicine and Healthcare; 2015August; 2(35):5426-5431; DOI:10. $18410 /$ jebmh/ 2015/ 754.
14. Banajeh SM, Outcome for children under 5 years hospitalized with severe acute lower respiratory tract infections in Yemen: a 5 year experience. $J$ Trop Pediatr. 1998 Dec; 44 (6): 343-6. doi: 10.1093/ tropej / 44.6.343.

15. Zhang Q, Guo Z, BaiZ, Mac Donald NE. A 4 year Prospective study to determine risk factors for severe community acquired pneumonia in children in southern China. Pediatr Pulmonol. 2013 Apr; 48 (4): 390397. doi: 10. 1002/ ppul. 22608. Epub 2012 Jul 6.

16. Technical basis for WHO recommendations on the management of pneumonia in children at first level health facilities. WHO/ART/ 91.20 Geneva: World Health Organization; 1991.

17. Integrated management of Childhood Illness (IMCI) (revised). Geneva, World Health Organization/ The United Nation Children"s Fund (UNICEF), 2014.

18. WHO. Recommendations for management of common childhood conditions: Evidence for technical update of pocket book recommendations. Geneva, WHO, 2012. http:// www. who.int/ maternal_ child_ adolescent/documents/management_childhood_conditio ns/en/index.html

\section{How to cite this article?}

Bekkam M, Vasundhara A. A study of risk factors for acute lower respiratory tract infections (ALRTI) in children aged 1 month to 5 years attending to a tertiary care hospital, Eluru, Andhra Pradesh, India. Int J Pediatr Res.2018;5(9):455-461. doi:10.17511/ijpr.2018.i09.05. 